\title{
Retrato e Fisionomia do Mundo em Cristóvão Colombo, o enigma
}

\author{
MARIA IRENE APARÍCIO \\ Universidade Nova de Lisboa
}

\begin{abstract}
This article considers how Portuguese cinema questions the possibility of any cinematic representation of national identity. By exposing the subjective mechanisms and the artistic construction of Manoel de Oliveira's Cristóvão Colombo, o enigma (2007), I argue that the film serves as a portrait despite being an affective landscape-what John Caspar Lavater has referred to as a physiognomic. Oliveira achieves this through the atemporal depiction of his own experience of the facts and fictions of Portuguese history. I also examine the Wagnerian concept of Gesamtkunstwerk ("total art”) along with more recent conceptions of "impure cinema."
\end{abstract}

Keywords: Manoel de Oliveira; Portuguese cinema; portrait; physiognomy; total art

Esta palavra saudade

Aquele que a inventou, A primeira vez que a disse Com certeza que chorou.

(Vieira 79)

A nossa proposta de análise dos valores transversais do retrato no cinema parte de uma proposição inicial: a asserção de que é frequentemente através desta forma ambivalente que o cinema convoca e questiona o valor potencial e subliminar da memória cultural, na legitimação de narrativas e ficções que se apresentam ao espectador como representações verosímeis da história. De resto, 
se é certo que a ideia de retrato é incontornável, ao menos na emergência de um cinema tendencialmente genérico e centrado no relato evocativo de personalidades (por exemplo, o biopic), também é evidente que em muitos filmes as celebridades convocadas não são apenas figuras eminentes da história, mas também obras, pedaços do mundo e da vida que se projetam assim positivamente ou negativamente no imaginário de uma comunidade, também ela imaginada. Neste sentido, trata-se aqui de compreender a relevância das formas de (des)figuração, abstração e abrangência do retrato, enquanto valor (in)tangível da imagética cinematográfica, a partir de uma breve análise do filme de Manoel de Oliveira, Cristóvão Colombo, o enigma (2007).

Pela observação da forma narrativa e respetivas imagens, procuramos mostrar em que medida o filme pode, por um lado, configurar geografias imaginárias, e por outro corroborar e/ou (des)valorizar uma ideia de comunidade, dando rosto a algumas figuras da história e das artes, disseminando-as, com maior ou menor transparência, ofuscando outras. Este processo contribui, indiretamente, para um movimento de ratificação ou redução do respetivo poder do arquivo, ao propagar, mas também ficcionar, os seus testemunhos. Além disso, é nossa convicção que, tanto a citação quanto a simples convocação imagética ou intertextual das figuras da história pelo cinema-que podemos talvez enquadrar no procedimento que o historiador Fernando Rosas designou por "usos públicos da história"-culminam frequentemente em narrativas ficcionais que transformam tanto a memória cultural como o valor documental das respetivas imagens (53).

Finalmente, é pertinente interrogar o âmbito do cinema acerca dos efeitos de propagação e resistência do valor de (uma) identidade, bem como das eventuais consequências epistemológicas da sua encenação, por exemplo a subalternização da dimensão factual perante outros valores-por exemplo, os da ficção e efabulação-que constroem ou destroem narrativas do passado, e respetivos mitos, contribuindo em simultâneo para a démarche processual de uma memória coletiva, e consequente ascensão de uma tensão civilizacional e ideológica que Rosas associa a uma ideia de "(des)memória," enquanto processo de manipulação da memória pelos movimentos contemporâneos de cultura, educação e comunicação. No verso desta mesma questão, Rosas aponta os efeitos consequentes da (des)memória: um "presente contínuo," "sem futuro 
e sem passado," "ahistórico," movimentos que um cinema da memória, ou até mesmo contra ela, poderá de algum modo contrariar. ${ }^{1}$

A outro nível, trata-se também de confrontar a evidência de uma dimensão do filme enquanto promotor de uma forma de "arte total." Tal conceito como pensado neste ensaio não se circunscreve ao sentido do vocábulo germânico e wagneriano de Gesamtkunstwerk, mas vai ao encontro da ideia enunciada e praticada pelas primeiras vanguardas artísticas ao incorporar o passado e o presente, assim transforma a sua própria especificidade. Alain Badiou alude a esta dimensão cinemática aditiva, global e globalizante do século XXI, que acaba por favorecer a função ideológica do filme, qualquer que seja a sua narrativa.

Para Badiou, muitos cineastas contemporâneos, entre os quais justamente Manoel de Oliveira (1908-2015), são protagonistas de uma "doutrina da Arte do cinema" que reenvia para o "carácter impuro desta arte" (223). Retomada a partir da proposição homónima de André Bazin (1918-1958) de um "cinema impuro," a proposta central de Badiou é que a ideia principal de um filme supõe um jogo complexo de convocação das outras artes (teatro, romance, música, pintura, etc.), bem como a décalage (deslocamento) da própria obra cinematográfica em relação às mesmas, pela contaminação da realidade e respetivos quotidianos. Em consequência, o cinema puro só existiria numa certa visão do formalismo vanguardista que, para Badiou, não teria qualquer hipótese de saída e continuação. Ele sugere, por isso mesmo, o alargamento do conceito de "cinema impuro" através da enunciação: "o cinema é um lugar de indiscernibilidade intrínseca entre arte e não-arte," o que implica que, no limite, nenhum filme é, na verdade, controlado por um pensamento artístico, na medida em que comporta "elementos" impuros que relevam da imagética ambiente, resíduos (por vezes no sentido mais negativo) das outras artes, convenções transitórias, etc. (223). O que parece ainda mais relevante neste contexto é que a ideia de uma atividade artística seria marcada no âmbito do cinema por um gesto de "depuração do seu carácter não-artístico imanente," sendo que o processo de purificação constituir-se-ia apenas como aproximação a um horizonte jamais alcançado (223). Deste modo, o objetivo pretendido e

\footnotetext{
${ }^{1}$ Rosas cita François Hartog a propósito desta questão: "Num sentido idêntico escreve François Hartog, ao referir o conceito de presentismo, um presente que 'sem futuro e sem passado,' ahistórico, permanentemente engendra os dois segundo as suas necessidades”” (67).
} 
supostamente atingido pelo cinema experimental seria, segundo Badiou-numa referência direta a Robert Bresson-uma forma de supressão da própria capacidade artística do cinema e, por arrasto, do seu alcance universal. Dito de outro modo, "as operações artísticas do cinema são operações de depuração inacabadas, apoiadas sobre as formas correntes não artísticas, sobre uma imagética insignificante [medíocre e popular] (as 'peintures idiotes' de Rimbaud)" (223). Para Badiou, daqui resultaria que as formas dominantes da não-arte são imanentes à própria arte e fazem parte da sua inteligibilidade, alegando o autor a necessidade permanente de indagar sobre as correntes formais dominantes na produção, e de assinalar os "esquemas circulantes [leiase, também, industriais e comerciais] do visível e do audível," na medida em que são eles que enformam, eventualmente, a prática das operações artísticas (223).

No entanto, ao situar o cinema numa fronteira ambivalente que parece afastá-lo da sua hipotética forma artística, Badiou não chega, ainda assim, a subtraí-lo totalmente aos desígnios de um movimento eclético de transversalidade e globalidade, nem ao paradoxo do seu "particular no universal," aqui num movimento talvez inverso ao do cinema expressionista que justamente tão bem revelou o "universal no particular." Por conseguinte, é nossa convicção que o gesto de desmembramento e fragmentação da realidade pelo cinema - como processo de depuração continua da sua própria formasurge assim como um dos métodos possíveis para veicular o valor de um plano intra-fílmico integral, ao mesmo tempo que evidencia o poder paradoxal do retrato cinematográfico, enquanto fisionomia da realidade, e respetivas projeções ideológicas. Veremos que, no caso do filme em análise, a fisionomia se amplifica, revelando-se através de um retrato "escrito" (por exemplo, uma assinatura) ou esculpido, mas manifestando-se também na complexa construção da sua personagem histórica central — Cristóvão Colombo - que pode revelar-se pela mise en scène de uma "obra de arte [quase] total," mas sobretudo pela forma de um "cinema impuro," cuja imagem advém simultaneamente da realidade (e do presente), da história e da imaginação. Só através de sucessivas fusões e dissociações, o espectador de Cristóvão Colombo, o enigma pode aceder às múltiplas camadas do tempo e do espaço que o compõem, jogando o jogo do cinema e compondo o puzzle - o enigma - da identidade desta figura. Uma identidade descomunal, cujos vestígios se encontram disseminados pelas 
obras -históricas, artísticas, etc.-e sobretudo por uma memória (frequentemente ausente, como no caso da figurante de Cuba), que se vai tecendo e desfazendo como a teia de Penélope.

\section{Uma (não) “arte integral”}

A primeira noção de uma "arte integral" surgiu, pela primeira vez, nos escritos de Zurique do compositor alemão Richard Wagner (1813-1883), em particular em A obra de arte do futuro (1849) e A arte e a revolução (1849), nas quais o autor expressa convictamente a sua crença de que o artista do futuro não é uma individualidade - um poeta, um pintor, um músico, um escultor, etc. - mas um coletivo. Seguindo a interpretação de Rolf J. Goebel, embora Wagner não dissesse explicitamente, tal artista seria o próprio Volk (496).

Em A arte e a revolução, Wagner traça um diagnóstico sombrio da arte em tempo de revolução, refletindo sobre o respetivo papel na sociedade do seu tempo. Num discurso encomiástico da tragédia grega, Wagner argumenta em favor da urgência de uma (nova) arte que se expresse a si própria, mas ao mesmo tempo possa expressar uma espécie de "consciência coletiva," tal como acontecia na tragédia onde "o Grego se encontrava a si mesmo, [e] sobretudo, reencontrava a parte mais nobre de si próprio enlaçada com os mais nobres elementos da essência geral do conjunto da nação" (43). Sabemos o quanto estas ideias - associadas ou não a outros escritos e, também, a alguma óperas mais controversas do compositor, como é o caso de Parsifal (1857-1879) foram muito oportunamente apropriadas pelo regime do Terceiro Reich (Adolf Hitler foi um admirador confesso de Wagner e das suas óperas), e o modo como a ambiguidade e a utopia das mesmas parecia ajustar-se - à semelhança dos primeiros filmes de Fritz Lang (1890-1976) — ao propósito de uma ideologia totalitária assente numa configuração ideal de um "povo."

Referindo-se à cultura clássica e à sua profunda influência no curso da cultura ocidental, Wagner sublinharia a relação entre a desagregação do Estado Ateniense e o declínio da tragédia grega, bem como uma das suas consequências: o recuo da arte perante a filosofia. Assinalando o paralelismo entre a desintegração do "espírito coletivo" e a dissolução da tragédia, Wagner sublinha a perda dessa "grandiosa obra de arte total," dispersa e assimilada enfim pelos seus próprios elementos artísticos (A arte e a revolução 44). $\mathrm{O}$ 
declínio é ainda revelado pelo "riso louco, [de] Aristófanes, o comediógrafo, [que] chorava sobre as ruínas da tragédia," decadência que levaria à extinção de "todo o impulso artístico . . p perante a gravidade do sentido de uma Filosofia que refletia sobre as causas da transitoriedade da beleza e do vigor humanos. Os dois milénios que transcorreram desde o ocaso da tragédia grega até aos nossos dias não pertencem à arte, mas sim à Filosofia" (A arte e a revolução 44).

Wagner utiliza a ambivalência — confrontação e delegação do ideal e do valor sensível da Arte, na ação de uma Filosofia conduzida pela faculdade de julgar - para assinalar a distância e o afastamento da arte enquanto "elevada atividade de um Homem que desenvolveu em si a beleza sensível e que é capaz de se achar em uníssono com a natureza e consigo mesmo" (A arte e a revolução 50). O seu oposto é o surgimento do "artista moderno . . . amarrado a um contrato e a um salário," isto é, dependente de um sistema capitalista determinado pelas relações de produção, onde a atividade produtiva é orientada para necessidades prementes, não deixando à arte um espaço necessário de liberdade essencial (A arte e a revolução 71). Ora, o que era determinante para Wagner era a urgência de confrontar este processo de criação alienado, afastando-o de todas as tendências de uma "indústria da cultura" onde imperava o culto da "riqueza material," a "especialização técnica" e a separação, em direção a uma condição integradora e libertadora; "a obra de arte do futuro" (A arte e a revolução 71). Depois de ter "esboçado a essência da obra de arte em que todas as artes hão de dissolver-se," Wagner concluiria que "a obra de arte do futuro é coletiva, e só pode decorrer de um desejo coletivo"; o da expressão do drama enquanto modalidade artística, já que, para o compositor, a ação dramática é passível de uma universalidade que lhe garante a compreensão máxima, mesmo pelos públicos menos preparados (A obra da arte do futuro 196). Para Wagner, a arte extrai o respetivo dramatismo da vida passada ou presente, numa relação de "máxima fidelidade à verdade," o que faz dela um espaço privilegiado de entendimento da vida e das suas vicissitudes (A obra da arte 196-97). Em nosso entender, é justamente esta imbricação da arte com a vida que incorpora ambos os seus constituintes - arte e não-arte-emoção e razão nos seus movimentos de excesso e êxtase, bem como nos momentos de estase.

Chegados a este ponto, é pois o momento de compreender em que medida a ideia wagneriana de Gesamtkunstwerk teve-e talvez continue a ter, ainda que 
Aparício

paradoxalmente - ecos e reflexos quer na definição, quer na reconfiguração dos campos de ação das artes e, em particular, da prática cinematográfica. Neste contexto, é oportuno relembrar os autores e cineastas que, nas primeiras décadas do século XX, reclamaram para o cinema esse estatuto de "obra total" que Wagner reconhecia à música no seu género operático. É o caso do manifesto e do cinema de Germaine Dulac (1882-1942), uma das vozes das primeiras vanguardas francesas que, no rescaldo da I Guerra Mundial, defendia a ideia de "cinema integral," na senda das ideias do primeiro percursor teórico dessas mesmas vanguardas, Ricciotto Canudo (1879-1923), musicólogo, ensaísta, romancista, poeta, crítico teatral e autor dramático. ${ }^{2}$ Italiano radicado em França, Canudo escreve o Manifesto das sete artes e estética da sétima arte (1923), assumindo definitivamente o cinema como arte — a sétima — de fusão. Uma arte que potencia a dimensão plástica das artes do espaço (arquitetura, pintura e escultura), ao mesmo tempo que eleva ao seu expoente máximo os ritmos das artes do tempo (música e poesia, e a dança). Canudo parte de uma ideia de universalidade das diversas artes, inscrevendo o cinema no mesmo sistema e considerando o filme como uma arte plástica em movimento. Veremos que esta proposta é um desafio aos limites epistemológicos da arte e, em particular, a essa sétima que acabava de nascer.

Segundo Canudo, os povos parecem ter quase todos as mesmas formas de expressão estética perante o mundo que os rodeia (a música e a poesia; ou a arquitetura, com os seus dois complementos: a escultura e a pintura). A vida estética do mundo estaria então exposta através das cinco expressões supracitadas, e à primeira vista, diz Canudo, seria inconcebível pensar no surgimento de uma sexta arte. Ainda assim, contra todas as expectativas, há mesmo uma sexta arte que se impõe, combinando de forma exímia as artes do espaço com os ritmos do tempo. Canudo refere-se ao teatro, que fora, até então, o conciliador destas duas vertentes da expressão humana. Contudo, ele aponta a sua única falha: a identificação com os atores, e a condição efémera resultante da sua forma ou performa - isto é, da sua condição performativa—que o tornava diverso e de difícil delimitação. Neste contexto, diz Canudo, a nova forma de expressão deveria ser "uma pintura e uma escultura, desenvolvendo-se no tempo, tal como a música e poesia" ("La naissance" 32). Para Canudo, tal

\footnotetext{
${ }^{2}$ Sobre as ideias de Dulac, ver Williams.
} 
como para Dulac ou Jean Epstein (1897-1953), terá sido justamente o cinematógrafo a indicar a direção, sendo que a nova expressão estaria definitivamente ligada, não ao que se conhece —à representação do visívelmas ao que ainda ou para sempre se desconhece; isto é, o que pela nossa limitada condição percetiva não conseguimos ver, mas que é suscetível de desencadear novas emoções e conhecimentos.

Convém lembrar que para os teóricos e cineastas das primeiras décadas do século XX, o cinema prometia então uma espécie de obra-síntese, resultado de um enlace essencial entre as artes do tempo e as artes do espaço. Não seria, portanto, mais uma no sistema das artes, mas a obra de arte por excelência, aquela que dialeticamente poderia combinar, incorporar e assimilar não só elementos plásticos das outras artes, mas também da realidade. O cinema seria, finalmente, "um movimento maravilhosamente combinado de imagens fotográficas e de luz, [onde] a vida é representada no auge da ação numa verdadeira convulsão paroxísmica . . . o indício de uma nova arte" (Canudo, "Triomphe" 188). Canudo considera esta nova arte o "arguente" da própria natureza, a qual é expressa através da sua dimensão plástica: "O essencial pelo visível. Tal como na música e na poesia mais modernas . . . procura-se a expressão do essencial pelo sensível" ("La leçon" 491-95). Canudo sublinha também a extrema consonância das duas artes-música e cinema-que assumem uma função universalista, tanto pelas suas formas quanto pelos seus conteúdos: "Sabemos que a música, pela expressão indefinida dos estados de alma, pela sua evocação dos nobres sentimentos elementares, sem a precisão rígida dos pensamentos e das palavras, pode ser considerada uma 'língua universal"” ("Musique et cinéma" 72). Já o cinema é uma "linguagem nova," trazida "aos homens novos que nós somos. . . Mais precisa do que a música, esta linguagem é, por si só, mais 'universal.' Porque nos dá um conhecimento íntimo dos povos, mais do que o livro, mais do que as harmonias sonoras" ("Musique et cinéma" 73).

No movimento de Canudo, ora convergente ora divergente, em direção a uma ideia de "língua universal" (que Epstein também defenderia), parece haver uma evidente ressonância do ideal wagneriano de Gesamtkunstwerk nesta proposta de especificidade da sétima arte, sobretudo nesse aspeto essencial de identificação da obra com o imponderável, bem como com o quotidiano e o social. João Mário Grilo cita o próprio Canudo ao destacar que: “o cinema 
Aparício

nasceu para ser a representação total das almas e dos corpos, um conto visual feito de imagens, pintado com pincéis de luz" (49). Esta visão algo poética do filme como forma sui generis de retratar a humanidade, mas acima de tudo a realidade - isto é, de representação dos corpos nas paisagens que os circundam e lhes moldam a almas - será doravante e recorrentemente invocada por outros autores. No entanto, são estas reflexões de Canudo sobre o cinema como linguagem e língua universal que primeiro revelam a dimensão de modernidade do objeto fílmico, invocando os ambientes fervilhantes da cidade do final do século XIX. Esta é também a paisagem descrita por Charles Baudelaire (18211867) e certeiramente referida por Walter Benjamin (1892-1940) como espetáculo da decadência consubstanciado nos ambientes degradantes das fábricas. Esse mesmo espetáculo não mais abandonaria até aos nossos dias a paisagem como retrato da humanidade, e que o cinema pressentiu desde o seu início, por exemplo, nos escassos mas paradigmáticos 45 segundos do primeiro filme de Auguste e Louis Lumière, La sortie de l'usine Lumière à Lyon (1895). De resto, a atestar esta impressão espetacular de um retrato industrial na viragem do século, Portugal terá também um filme correlato, produzido em 1896 por Aurélio Paz dos Reis (1862-1931), sob o título, Saída do pessoal operário da fábrica Confiança, filmado na cidade do Porto e considerado o primeiro filme português.

Ao relembrar as origens, bem como as reflexões que fizeram do cinema o que ele é hoje, podemos compreender a resistência quer das suas práticas quer das teorias, num contexto global e globalizante onde o filme tende a definir-se como resultado de um processo assalariado, tributário das relações de produção, enfim, como produto de uma indústria cultural cuja demanda mantém a mesma ambiguidade que Wagner encontrava na então designada "arte moderna." Esta mesma condição induz-nos a questionar o cinema do ponto de vista da sua resiliência, propondo uma ideia de valor das suas imagens que é indissociável de uma intenção de "liberdade intrínseca" da própria obra, e que a autoriza a revelar (mesmo quando censurada) uma dimensão de realidade - a sua fisionomia-que se traduz em sintomas literalmente impressionados, nomeadamente através da mise en scène e das respetivas formas fílmicas. Isto é, pela inscrição e revelação de retratos e paisagens que não podem dissociar-se da (sua) história e dos (nossos) caminhos futuros, e que, para o bem e para o mal, abrem o espaço infinito de ação de uma memória dita cultural. 
Epstein reclamaria para o cinema a capacidade de sondar a alma humana, através do grande plano do rosto. Bela Bálàzs encontra nesse retrato um dos traços mais sublimes da nova arte (51); uma aura que até mesmo Benjamin acaba por reconhecer à fotografia do rosto, apesar das perdas da arte face à tecnologia (226). Benjamin sublinha a questão crucial do retrato nos primórdios da fotografia, bem como destaca a sua função no "culto de rememoração dos entes queridos, ausentes ou mortos" (226). Nesse sentido, Benjamin propõe o retrato como o último reduto para o "culto do valor da imagem. [Já que,] pela última vez, a aura emana das primeiras fotografias, na expressão fugaz e transitória de um rosto humano. É isto que constitui a sua melancolia, incomparável beleza" (226).

É, então, nesse intervalo entre a proficiência do gesto do pintor na procura da justa nuance do pigmento e invenção da fisionomia possível daqueles que permanecem na memória coletiva, embora sem corpo e sem rosto, que os retratos cinematográficos dos filmes de Oliveira cruzam as questões da "obra de arte total" enquanto forma de composição estética e ética, tanto da realidade como da vida. Baseada num relato autobiográfico e nas teorias históricas de Manuel Luciano da Silva e Sílvia Jorge da Silva, veremos como estas ideias de "obra de arte total" se ajustam ao filme de Oliveira, na medida em que a sua estória configura uma ética pela procura de uma origem e identidade, ao mesmo tempo em que desenha esteticamente uma impossibilidade de reversão do tempo e de retorno ao passado, através de uma narrativa não linear, enigmática no início e saudosista no final.

\section{Retrato(s)}

Pascale Dubus identifica cinco problemáticas associadas à ideia de retrato: a sua relação com a invenção das artes visuais, os dois conceitos de corpo e figura, a questão do espectador e, finalmente, a ligação incontornável com a finitude humana. Dubus recupera a fábula de Butades, contada por Plínio na sua História natural, metáfora frequente nos tratados de pintura do século XV. Tal metáfora alude à silhueta do amado de sua filha que, ao conferir-lhe uma identidade e uma presença, reporta a relevância dessa mesma silhueta no processo de uma dimensão plástica, plasticidade esta que estaria na origem da pintura, mais precisamente do retrato. Este retrato - ainda que tirado do traçado 
da sua sombra-estaria, também, claramente ligado a uma ideia de representação no sentido original de "tornar presente," ao qual a "equação mimética" não é alheia. ${ }^{3}$ Por "equação mimética" entendemos aqui a relação entre a aparência externa de um ser e a sua apreensão, no sentido em que, nas palavras de Nicolau de Cusa, "toda a similitude é uma imagem ou um signo de igualdade" 'Similitudo autem omnis est aequalitatis species seu signum' (247). Assim, do ponto de vista estético, o retrato referir-se-ia à forma plástica de fixação dos traços de uma pessoa determinada numa imagem, e às suas referências em contextos de história civilizacional, bem como religiosos, enquanto profundamente significantes do seu valor. Embora estas questões sejam muito relevantes, interessa-nos aqui a convocação da ideia de fisionomia anteriormente citada, que esteve na base de várias leituras e interpretações filosóficas posteriores, tais como as que propunham as ideias de "fisionomia do mundo" (Benjamin), "rosticização" (Gilles Deleuze) ou ainda de "assinatura de todas as coisas" (Giorgio Agamben). É esta fisionomia transversal que convocamos para falar da emergência de uma forma de paisagem interior ou retrato da alma numa relação dinâmica com a paisagem do mundo. Neste trajeto, o modo como o cinema de Oliveira esboça o ser e a forma do mundo é tributário do valor do próprio processo de criação, questão que tem uma profunda condição histórica e ideológica.

Convocando a pouco sistematizada proto-história do cinema, afirmarmos que a origem comum e a supremacia da visualidade caucionam a ligação umbilical entre o cinema e as outras artes; nomeadamente uma relação incontornável com a perceção humana e a ligação desta condição à convicção de que a representação, qualquer que seja o medium, mantém um elo com a realidade. Estas questões levar-nos-iam a outras igualmente relevantes, mas por agora, é no horizonte deste vasto enquadramento teórico-e na senda destas questões forçosamente dispersas - que fazemos uma aproximação à questão dos valores e configurações do retrato no filme de Oliveira.

O que Cristóvão Colombo, o enigma possui em comum com o retrato propriamente dito é o facto de se reportar a uma história facilmente identificada pela sua figura principal. Como em outros filmes, Oliveira persegue o estudo das fisionomias da história. Cristóvão Colombo, o enigma é um filme

\footnotetext{
${ }^{3}$ Ver, por exemplo, Regnault.
} 
ensaístico, particular e subjetivado que, tal como o estudo da fisionomia para Lavater, culmina na expressão dos sentimentos. É um exercício que estimula a sensibilidade, promovendo o poder de transmissão dos eventos particulares da história e da arte que glorifica o passado, através do museu, da escultura, da fotografia, da estatuária, da arquitetura, etc. O filme é, por esta via, o traçado de uma história que observamos através dessas múltiplas obras-fisionomias de uma realidade que experienciamos e sentimos, como indivíduos e como nação, enquanto comunidade imaginada. Apesar do enigma, Oliveira pesquisa, circunscreve e cataloga o que Lavater designou como "os signos visíveis de poderes invisíveis. [O que] significa, também, descobrir causas e efeitos da expressão . . . através dos traços fisionómicos e suas alterações" (19); é uma assinatura (sempre um traço indelével da individualidade), um nome, uma casa, uma linhagem, uma estátua, um monumento (19).

Há efetivamente no trabalho de representação desta e outras figuras da história de Portugal uma clara fixação num tempo passado e nos factos que condicionaram as vidas destas personalidades - e de certo modo também as nossas-através do arquivo e da memória. Mas há, sobretudo, manchas e traçados invisíveis desses retratos que excedem as figuras representadas a partir da incorporação de outros retratos descritos, esculpidos, etc.; gestos e trejeitos inventados, embora verosimilhantes, narrativas alegóricas de pós-memória, enfim, memórias ficcionadas (Aparício).

\section{(Auto)Retratado(s): Cristóvão Colombo, o enigma e o cineasta}

Se recuperarmos as problemáticas associadas à ideia de retrato-a invenção das artes visuais, corpo e figura, espectador e memento mori-notamos o modo como Cristóvão Colombo, o enigma estabelece (ainda que involuntariamente) um elo com todas elas. O filme começa por uma imagem da escrita, da relevância visual (e, para os Silvas, histórica) da assinatura de Colombo e da franca ligação à gravura como forma de perpetuação do período histórico invocado. Poderíamos mesmo recorrer ao testemunho dessa outra invenção de uma arte também ela visual — a dos mapas — já que o próprio filme é o traçado de um mapa visual inscrito no tempo e não no espaço, o mapa das passagens, ou seja, dos lugares que ficaram até hoje ligados ao nome do navegador convocado. 
O corpo é aqui indiciado pela constante presença estatuária, mas a personagem ausente de Colombo excede esse corpo físico da escultura, afirmando-se como figura. Sem dúvida, o espectador é a linha temática mais importante deste retrato, já que é pelo imaginário daquele que vê que a estória de Colombo se inscreve num espaço e num tempo especificamente portugueses - a vila de Cuba no Alentejo, e a lusitana mitologia da saudade em pleno século $\mathrm{XX}$ - primeiro sondados pelos dois irmãos que partem para a América, tal como Colombo partiu, e depois pelas personagens de Manuel e Sílvia que repetem essa mesma viagem de ida e volta, num retorno às origens. Finalmente, este filme, tal como quase todos os outros de Oliveira, é uma subliminar alegoria da finitude humana.

O retrato de Colombo releva uma imagética que exprime bem a condição da brevidade da vida, na forma como expõe os efeitos do tempo; na abstração e no imaginário de uma figura cuja origem se apaga no horizonte da história, e pela qual as personagens do filme percorrem o país e o mundo durante uma (tão curta) vida. Neste movimento, o filme expõe uma tripla fisionomia da realidade. Primeiro, há o retrato possível de Colombo, a partir dos vestígios da sua assinatura no mundo. Segundo, há um (auto)retrato do cineasta que chega mesmo a tomar o lugar do personagem principal, e cujo amor pelo cinema é metaforizado pelo fascínio e dedicação da personagem à problemática da história. Finalmente, há a condição identitária de um Portugal que se apaga lentamente face ao futuro inadiável de um mundo globalizado. Ao terminar o

filme com um dos muitos poemas sobre a saudade escritos por Afonso Lopes Vieira (1878-1946), Oliveira também recobra os ideais de patriotismo humanista.

\section{Memória(s): uma breve conclusão}

Rosas fala de "uma inquietação" e "um desassossego intelectual . . perceção inquieta da subversão ideológica e de valores, que atravessa as sociedades do Ocidente" (47). Rosas procura abrir o sentido de uma ação efetiva do cinema, que está bem no centro das transformações socioculturais e políticas contemporâneas. Em nosso entender, o sobressalto de Rosas parece ser da mesma natureza daquele que agita algum cinema português nas últimas décadas e em particular o cinema de Oliveira, obsessivamente marcado pelo constante 
diálogo com a história e com os seus protagonistas. Essa obsessão traduz-se numa procura constante das fisionomias da realidade e respetivas ligações quer ao passado, quer ao futuro de uma comunidade por vir.

Cristóvão Colombo, o enigma é registo de uma subliminar preocupação com a influência da globalização na transformação de uma ideia vernácula de identidade, identidade esta sempre associada às fundações, aos descobrimentos e ao subsequente império colonial. Não sendo documentário nem drama, nos sentidos clássicos dos termos, é nessa indiscernibilidade de fronteiras que se questiona o desenho de um retrato do que é "ser português," bem como toda a ambiguidade dos vínculos da identidade aos limites geográficos de um espaço, ou à linear experiência de um tempo histórico. As suas personagens reais e profundamente ficcionadas são contemporâneas, e é através delas que o filme esboça um mapa imaginário das origens do navegador que terá chegado ao continente americano presumivelmente numa caravela espanhola em 1492, e cuja nacionalidade é reclamada por diversas nações, incluindo Catalunha, Espanha, Itália e Portugal.

O título do filme e o modo como o próprio se retrata e reflete num vocábulo profundamente significante invalidam qualquer tentação de o considerar um filme histórico. Trata-se, pelo contrário, de ensaiar uma obra de arte (quase) total, que convoca continuamente não só as outras artes, a história e as estórias, mas também um cinema impuro, no qual convergem vestígios do passado, marcas do presente e sintomas do futuro. Afinal, se um enigma é, por definição, uma descrição metafórica, ou mesmo um enunciado difícil de compreender que clama por uma decifração, o termo ajusta-se com propriedade ao filme de Oliveira. Por um lado, o filme procura na realidade os traços que lhe permitem esboçar o "retrato-ficção" dessa figura, mas por outro não chega a afirmar-se enquanto biografia, nem (pretende ser) um filme épico ou histórico. A sua fórmula é a de uma hypothesis, a suposição de um acontecimento genealógico possível, incerto. O filme não é uma resposta, mas uma pergunta.

A nossa tentativa de religar questões tão diversas como "obra de arte total," "cinema impuro," "fisionomia da realidade," "retrato cinematográfico" e "cinema português" está longe de esgotar o mapeamento possível destas temáticas. Na verdade, esta breve abordagem, transversal e parcial, foi conduzida pelo conceito de retrato, a partir de uma definição abrangente e não circunscrita à ideia convencionada de um modelo à imagem e escala humanas, 
Aparício

em detrimento de um trabalho de identificação do retrato no cinema, muito mais simples, mas também muito mais eficaz. Por isso, temos plena consciência que um trabalho exaustivo sobre estas questões poderia levar-nos a outras projeções do problema da identidade, por exemplo, incluindo o questionamento sobre o contributo real do cinema para a circulação, cristalização e transferência de uma memória dita cultural. Esse exercício será, aliás, continuado no nosso trabalho em curso, nomeadamente pela comparação deste filme com outros filmes, numa contextualização mais vasta de compreensão do cinema português na sua relação com a história e as outras artes.

\section{Obras citadas}

Agamben, Giorgio. Signatura rerum: sul metodo. Bollati Boringhieri, 2008.

Aparício, Maria Irene. "'Thanks for the Memories': As imagens depois da fotografia e do cinema." Fotogramas, ensaios sobre a fotografia, editado por Margarida Medeiros, Documenta, 2016, 25-36.

Badiou, Alain. "Considérations sur l'état actuel du cinéma, et sur les moyens de penser cet état sans avoir à conclure que le cinéma est mort ou mourant." L'art du cinéma, vol. 24, 1999, pp. 7-22.

Bálàzs, Béla. Bela Bálàzs: Early Film Theory: Visible Man and The Spirit of Film, traduzido por Erica Carter, Berghahn, 2011.

Baudelaire, Charles. Selected Letters of Charles Baudelaire: The Conquest of Solitude, translated by Rosemary Lloyd, U of Chicago P, 1986.

Benjamim, Walter. "The Work of Art in the Age of Technical Reproduction." Illuminations: Essays and Reflections, Schocken, 1969, pp. 217-51.

Canudo, Ricciotto. "La naissance d'un sixième art: essai sur le cinématographe." L’Usine aux images, Séguier, 1995, pp. 32-40.

- . "Musique et cinéma: langages universels." L’Usine aux images, Séguier, 1995, pp. 72-74.

—. "La leçon du cinéma." Le cinéma: naissance d'un art, premiers écrits (1895-1920), editado por Daniel Banda e José Moure, Flammarion, 2008, pp.491-95.

—. "Triomphe du cinématographe." Le cinéma: naissance d'un art, premiers écrits (1895-1920), editado por Daniel Banda e José Moure, Flammarion, 2008, pp. 185-98. 
Deleuze, Gilles. Le bergsonisme. Presses U de France, 1966.

Dubus, Pascale. Qu'est qu'un portrait. Insolite, 2006.

Goebel, Rolf J. "Gesamtkunstwerk Dresden: Official Urban Discourse and Durs Grünbein's Poetic Critique.” The German Quarterly, vol. 80, no. 4 (2007), pp. 492-510.

Grilo, João Mário. As lições do cinema: manual de filmologia. Colibri, 2017. Hartog, François. Régimes d'historicité: présentisme et expérience du temps. Seuil, 2003.

Lavater, John Caspar. Essays on Physiognomy: For the Promotion of the Knowledge and the Love of Mankind, Whittingham, 1804.

Nicolau, de Cusa. Opere. Petrina, 1565.

Regnault, Jean-Baptiste. "L'Origine de la peinture.” Óleo sobre tela, 1786, Château de Versailles.

Rosas, Fernando. História e memória: última lição de Fernando Rosas. Tinta da China, 2016.

Silva, Manuel Luciano da, e Sílvia Jorge da Silva. Cristóvão Colon (Colombo) era português. QuidNovi, 2006.

Wagner, Richard. A arte e a revolução, traduzido por José M. Justo, Antígona, 2000.

- A obra de arte do futuro, traduzido por José M. Justo, Antígona, 2003.

Williams, Tami. Germaine Dulac: A Cinema of Sensations. U of Illinois P, 2014. 